\title{
Reduced overpotentials in microbial electrolysis cells through improved design, operation, and electrochemical
}

\section{characterization}

Dongwon $\mathrm{Ki}^{1,2^{*}}$, Sudeep C. Popat ${ }^{2^{*}}$, César I. Torres ${ }^{2,3^{*}}$

${ }^{1}$ School of Sustainable Engineering and the Built Environment, Arizona State University, Tempe, AZ, USA

${ }^{2}$ Swette Center for Environmental Biotechnology, Biodesign Institute, Arizona State University, Tempe, AZ, USA

${ }^{3}$ School for Engineering of Matter, Transport and Energy, Arizona State University, Tempe, AZ, USA

* dongwonk@asu.edu, scp@asu.edu, cit@asu.edu 


\section{Abstract}

One of the main performance challenges in microbial electrochemical cells (MXCs) is the low voltage efficiency in comparison to other fuel and electrolysis cells. In this study, we aimed to improve the design and operation of microbial electrolysis cells (MECs) to achieve current densities $>10 \mathrm{~A} \mathrm{~m}^{-2}$ with reduced applied voltages, using a thorough analytical framework involving electrochemical techniques such as chronoamperometry, voltammetry and electrochemical impedance spectroscopy. We developed a design that allows high surface area for the anode using carbon fibers, but without creating a large distance between the anode and the cathode $(<0.5 \mathrm{~cm})$ to reduce Ohmic overpotential. We determined that Ohmic overpotential, at current densities $>10 \mathrm{~A} \mathrm{~m}^{-2}$ remained $<0.1 \mathrm{~V}$ even when using an anion exchange membrane to separate the anode and the cathode. We observed the largest overpotential from cathode related phenomena. The increase in $\mathrm{pH}$ in the cathode chamber, often to $\sim 13$, results in $>0.3 \mathrm{~V}$ of Nernstian concentration overpotential. We showed how by adding $\mathrm{CO}_{2}$ to the cathode, this overpotential could be reduced to negligible. We also tested two different cathode materials - stainless steel and nickel - to compare the cathode activation overpotentials. Overall, through our design and operation improvements, we were able to reduce the applied voltages from 1.1 to $\sim 0.85 \mathrm{~V}$, at $10 \mathrm{~A} \mathrm{~m}^{-2}$. Our results also provide important guidelines for further optimizations of MXCs.

Keywords: microbial electrolysis cells, design, operation, overpotential, voltage efficiency, microbial fuel cells 


\section{Introduction}

Microbial electrochemical cells (MXCs) represent a promising technology for the recovery of energy from waste organics either as electrical power or for production of useful chemicals such as hydrogen $\left(\mathrm{H}_{2}\right)$, hydrogen peroxide $\left(\mathrm{H}_{2} \mathrm{O}_{2}\right)$ and many others [15]. In MXCs, anode-respiring bacteria (ARB) oxidize waste organics, and generate an electrical current on the anode [6-8]. In the simplest form of anode respiration, acetate, a common product of anaerobic metabolism, is used as the electron donor (equation 1).

$\mathrm{CH}_{3} \mathrm{COO}^{-}+4 \mathrm{H}_{2} \mathrm{O} \rightarrow 2 \mathrm{HCO}_{3}^{-}+9 \mathrm{H}^{+}+8 \mathrm{e}^{-}$

At the cathode, these electrons reduce oxygen $\left(\mathrm{O}_{2}\right)$ to water or $\mathrm{H}_{2} \mathrm{O}_{2}$ in microbial fuel cells (MFCs) (equation 2), or water to $\mathrm{H}_{2}$ in microbial electrolysis cells (MECs) (equation $3)$, which requires a small voltage input [2, 9].

$\mathrm{O}_{2}+4 \mathrm{H}^{+}+4 \mathrm{e}^{-} \rightarrow 2 \mathrm{H}_{2} \mathrm{O}$ or $\mathrm{O}_{2}+2 \mathrm{H}^{+}+2 \mathrm{e}^{-} \rightarrow \mathrm{H}_{2} \mathrm{O}_{2}$

$2 \mathrm{H}_{2} \mathrm{O}+2 \mathrm{e}^{-} \rightarrow \mathrm{H}_{2}+2 \mathrm{OH}^{-}$

Several different aspects of MXC processes have shown major progress in the last few years, including understanding extracellular electron transport (EET) in ARB [1013], managing microbial communities to achieve high Coulombic efficiencies [14-17], and developing new, cheaper materials for electrodes and separators [18-20]. However, one of the major limitations still hindering the application of MXCs is the low voltage efficiency $[3,21]$. In the case of MFCs, a theoretical maximum of $1.1 \mathrm{~V}$ is available when coupling acetate oxidation at the anode to $\mathrm{O}_{2}$ reduction at the cathode. Yet, at current densities of $>5 \mathrm{~A} \mathrm{~m}^{-2}$, only $<0.3 \mathrm{~V}$ is produced, representing $>0.8 \mathrm{~V}$ of overpotential $[17,19,22]$. Similarly, although the theoretical applied voltage in MECs is only $0.14 \mathrm{~V}$, the actual applied voltage can be as high as $1.2 \mathrm{~V}$, representing close to $1 \mathrm{~V}$ of overpotential [23-26]. Such large overpotentials are in stark contrast with most other fuel cells or electrolysis cells, where orders of magnitude higher current densities are 
possible at lower overpotentials [27-28]. There is thus a need to consider design and operation tactics for MXCs that help reduce the overall overpotential in the system.

Overpotentials in electrochemical systems are always classified into three major types: activation, Ohmic, and concentration overpotentials [29]. Activation overpotential is related to the activation barrier for a given electrochemical reaction, and the properties of the catalysts in overcoming the activation barrier. In the case of the anode reaction in MXCs, activation overpotential relates to the energy lost in the oxidation of the electron donor by the ARB to metabolism. Likewise, cathode activation overpotential relates to the energy loss at cathode during reduction of $\mathrm{O}_{2}$ to water or $\mathrm{H}_{2} \mathrm{O}_{2}$ in MFCs or of water to $\mathrm{H}_{2}$ in MECs. Ohmic overpotential is related to the transport of ions between the anode and the cathode, and depends on the conductivity of the electrolyte. In the case of MXCs, low conductivity solutions are used for the growth of ARB, and thus this results in high Ohmic overpotential if the distance between the two electrodes is large. Thus, to reduce Ohmic overpotential, it is imperative that we reduce distances between the anode and the cathode, as previously suggested by many other studies [23, 30-32].

Concentration overpotential is related to Nernstian and activation losses resulting from not being able to maintain the concentrations of reactants on the electrode surface as well as not removing products from the electrode surface at a fast enough rate. The most common form of concentration overpotential acknowledged for MXCs is due to the $\mathrm{pH}$ imbalance that results between the two electrodes when using a membrane to separate the electrodes [2,33]. For every $\mathrm{pH}$ unit the cathode $\mathrm{pH}$ is higher than the anode $\mathrm{pH}$, a Nernstian concentration overpotential of $\sim 60 \mathrm{mV}$ results. We showed recently that even when bulk concentrations are the same, for e.g. in the absence of a membrane, differences in electrode surface concentrations can still lead to a high concentration overpotential [34]. 
In this study, we aim to systematically characterize and reduce all overpotentials in an MEC. Although we use an MEC here, the results should directly apply to all other MXCs that use a microbial anode with an inorganic catalyst-based cathode. We started with a logical design for the MEC with reduced distance between the anode and the cathode, and high surface area electrodes. From thereon, based on the characterized individual overpotentials, we modified the materials and the operating conditions we used to reduce the overall overpotential and thus the applied voltage. We show here how it is possible to reduce applied voltages in MECs at a current density of $10 \mathrm{~A} \mathrm{~m}^{-2}$, from $1.1 \mathrm{~V}$ to $\sim 0.85 \mathrm{~V}$, thus representing only $\sim 0.7 \mathrm{~V}$ of overpotential. We also provide a perspective on ways to reduce further overpotentials as well as a limit to the overall voltage efficiency possible in MXCs. 


\section{Materials and methods}

\subsection{MEC design and operation}

We designed modular flat-plate MECs each with two anodes and two cathodes as described in our previous study [35]. We provide a schematic and photos in Figure S1. Briefly, the anodes were made of carbon fibers (24K Carbon Tow, FibreGlast, $\mathrm{OH}$, USA) that were woven around a titanium plate that served as current collector (each anode was $10 \mathrm{~cm} \times 10 \mathrm{~cm}$, geometric area of $100 \mathrm{~cm}^{2}$ ). A photograph of an assembled anode is shown in Figure S1(c) in the Supporting Information. The two anodes shared a common chamber. We used stainless steel meshes (Type 314, McMaster-Carr, USA) or nickel meshes (Ni 200, Unique Wire Weaving Co., Inc., USA) as the cathodes, and each cathode had a separate individual chamber. We cleaned the assembled anodes with 1 $\mathrm{M}$ nitric acid for 3 hours, $1 \mathrm{M}$ acetone for 12 hours, $1 \mathrm{M}$ ethanol for 3 hours, and deionized water (18 M $)$ ) overnight before using them. We equipped the anode chamber with a reference electrode (Ag/AgCl, MF-2052, Bioanalytical Systems, Inc., USA), which was at a $\sim 2 \mathrm{~cm}$ distance from each anode. All potentials we report throughout are converted to vs. standard hydrogen electrode (SHE) using a conversion factor of +0.27 V. We determined this conversion factor as previously described for the medium we fed to the MECs [36]. We used the anion exchange membranes AMI-7001 (Membrane International, Glen Rock, NJ) or Fumasep FAA (FuMa-Tech, Germany) to separate the anode and the cathode chambers. We maintained the distance between the anode and cathode at $<0.5 \mathrm{~cm}$. The anode chamber volume was $\sim 0.5 \mathrm{~L}$ and the cathode chamber volume (individual) was $\sim 0.1 \mathrm{~L}$ (or $0.2 \mathrm{~L}$ total). The anode was fed with acetate as the electron donor (see medium composition below), while the cathode was fed with a 100 $\mathrm{mM}$ solution of $\mathrm{NaCl}$ or $\mathrm{NaOH}$. 
We inoculated the MECs with a mixture of anaerobic digested sludge $(2 \mathrm{~mL}$, obtained from Mesa Northwest Wastewater Reclamation Plant in Mesa, AZ, USA) and the effluent from a continuously fed MEC in our laboratory fed with acetate as the electron donor (248 mL). We operated the MECs in batch mode initially, followed by continuous flow of the anode medium at a rate of $0.3-0.5 \mathrm{~mL} \mathrm{~min}^{-1}$, resulting in a hydraulic retention time of 16.7-27.8 h. The anode feed consisted of $50 \mathrm{mM}$ acetate, $100 \mathrm{mM}$ phosphate buffer (PBS, $85 \mathrm{mM}$ of $\mathrm{KH}_{2} \mathrm{PO}_{4}$ and $15 \mathrm{mM}$ of $\mathrm{Na}_{2} \mathrm{HPO}_{4}$ ), $14 \mathrm{mM}$ ammonium chloride, and trace minerals [6]. The $\mathrm{pH}$ of the medium was $\sim 7.6$. We operated the MECs in a temperature-controlled room at $30^{\circ} \mathrm{C}$. We sparged the anolyte and catholyte with ultra-high purity nitrogen gas (>99.999\%) to remove $\mathrm{O}_{2}$ before feeding to each chamber. For experiments where we added $\mathrm{CO}_{2}$ to the cathode (see text in Results and Discussion), we used $100 \% \mathrm{CO}_{2}$ that was sparged into an external chamber containing the catholyte. The $\mathrm{CO}_{2}$ flow rate was $250 \mathrm{~mL} \mathrm{~min}^{-1}$ and we recirculated the catholyte within the cathode chambers at $20 \mathrm{~mL} \mathrm{~min}^{-1}$ flow rate (Figure S2). We set the anode potential at $-0.03 \mathrm{~V}$ with a multi-channel potentiostat (VMP3, BioLogic Science Instruments, Knoxville, TN), and recorded current, and anode and cathode potential every two minutes. This anode potential was selected on the basis of a previous study that has shown that the potential is oxidizing enough to allow optimum growth of known ARB [36].

After a stable current was obtained, we developed $j$ - $V$ curves using chronoamperometry starting from the open circuit potential up to the anode potential resulting in the highest saturation current densities, stepping the potential $25 \mathrm{mV}$ for each data point. We waited $\sim 10$ minutes for steady current at each potential before stepping up the anode potential. At the end of each experiment, we performed electrochemical impedance spectroscopy (EIS) measurements at $100 \mathrm{kHz}$ with an amplitude of $10 \mathrm{mV}$, while using the anode as the working electrode and the cathode as 
the counter and reference electrode to determine the Ohmic resistance between the anode and the cathode. The Ohmic resistance used was an average value from 20 measurements. We also performed $i R$ correction for all anode and cathodes potentials by doing EIS measurements in the same way as described above but with the anode or the cathode as the working electrode and the $\mathrm{Ag} / \mathrm{AgCl}$ reference electrode as the reference.

\subsection{Electrochemical impedance spectroscopy of MEC cathodes}

To characterize the performance of the cathodes we used in the MECs during operation (with or without addition of $\mathrm{CO}_{2}$ to the cathode), we performed potentiostatic EIS measurements at each condition at various cathode potentials. We used an amplitude of $10 \mathrm{mV}$, with a frequency range of $100 \mathrm{kHz}$ to $10 \mathrm{mHz}$. We took six data measurements per decade of frequency. We fit the Nyquist plot data using an equivalent circuit model containing two charge transfer resistances in series with an Ohmic resistance. For each cathode potential, we report a total area-specific resistance, which is the sum of the two charge transfer resistances.

\subsection{Tests for selection of materials for enhanced MEC performance}

\subsubsection{Characterization of anion exchange membranes}

We characterized various commercially available AEMs (Table 1) to use in our MECs when adding $\mathrm{CO}_{2}$ to the cathode. We used AEMs since it has been showed that when electroneutrality is maintained by transport of $\mathrm{OH}^{-}$from the cathode chamber to the anode chamber, either directly or via carbonate and/or bicarbonate species, the $\mathrm{pH}$ on the anode can be maintained close to 7 [37-38]. For the AEM characterization, we used electrochemical cells containing two chambers filled with $100 \mathrm{mM} \mathrm{NaHCO}$. We performed EIS on the cell with one stainless steel rod $\left(\approx 9 \mathrm{~cm}^{2}, 5 \mathrm{~mm}\right.$ diameter $)$ as the working electrode, and another as the counter and reference electrode, using a 
frequency of $100 \mathrm{kHz}$ and an amplitude of $10 \mathrm{mV}$. This allowed measurement of the Ohmic resistance between the two electrodes for the various AEMs. We also performed EIS analysis without a membrane to obtain the Ohmic resistance just from the liquid electrolyte used, thus making it possible to determine the resistance to ion transport from the AEMs only from subtraction. We show a list of the membranes tested in Table 1 along with their thickness and $\mathrm{pH}$ stability range.

\subsubsection{Characterization of cathode materials}

For testing and comparing the performance of different cathodes for use in the MECs, we used a flat-plate two-chamber electrochemical cell having the same volume (100 mL) for each chamber. We used a stainless steel mesh electrode (SuperCorrosion-Resistance Type 316 Stainless Steel Mesh, SS [20 x 20 wires/inch] (McMaster-Carr, USA) or a nickel mesh electrode, Ni 200 [70 x 70 wires/inch] (Unique Wire Weaving Co., Inc., USA) of size $7 \mathrm{~cm} \times 7 \mathrm{~cm}\left(49 \mathrm{~cm}^{2}\right.$ projected area) as the cathodes. We provide more information on the two materials in Table S1 in the Supporting Information. We used AMI-7001 as the membrane, and the same Ni mesh electrode as the counter electrode for all tests. For the electrolyte, we used $100 \mathrm{mM}$ $\mathrm{NaOH}$ solution in both chambers.

We performed linear sweep voltammetry (LSV) on the cathodes at $30^{\circ} \mathrm{C}$ at a scan rate of $10 \mathrm{mV} \mathrm{s}^{-1}$. Before performing LSV, we measured the Ohmic resistance by EIS and applied $i R$ correction during the LSV. We repeated the LSV for at least three times for each material. 


\section{Results and discussions}

\subsection{Characterization of overpotentials in MECs}

We first performed chronoamperometry to obtain $j-V$ curves for an MEC constructed with stainless steel mesh cathodes (SS-1) and AMI-7001 membranes

(Figure 1a, Experiment 1 in Table 2). We performed at least two replicate measurements to obtain the curves for each condition and show only one representative set here. All replicates followed the same trend and an additional representative set is shown in the Supporting Information (Figure S3).

We divided the total overpotential into four individual overpotentials: (i) anode overpotential resulting from ARB metabolism, (ii) Ohmic overpotential, which is related to ion transport between the anode and the cathode, (iii) concentration overpotential related to an increase in the cathode chamber $\mathrm{pH}$ due to low concentration of $\mathrm{H}^{+}$or high concentration of $\mathrm{OH}^{-}$, and (iv) cathode overpotential, which includes cathode activation losses and potentially any concentration losses related to different local concentrations of reactants and products from the bulk electrolyte. The overall applied voltage in the MECs is then the sum of all overpotentials and the theoretical applied voltage necessary, as per the following equation.

$E_{a p}=E_{T h}+\eta_{p H}+\eta_{\text {ohmic }}+\eta_{c a}+\eta_{a n}$

where $E_{a p}$ is the applied voltage, $E_{T h}$ is the theoretical voltage necessary, $\eta_{\text {Ohmic }}$ is the Ohmic overpotential, $\eta_{p H}$ is the concentration overpotential due to increased cathode $\mathrm{pH}$, $\eta_{c a}$ is the cathode overpotential, and $\eta_{a n}$ is the anode overpotential. The applied voltage $\left(E_{a p}\right)$ was the difference between the anode and cathode potentials measured with the potentiostat. The theoretical voltage $\left(E_{T h}\right)$ is the energy needed to overcome the thermodynamic barrier for $\mathrm{H}_{2}$ production in MECs. We calculated this with the Nernst equation with known acetate and bicarbonate concentrations, and pH, 
$E_{T h}=E_{c a}-E_{a n}=\left(E_{c a}^{0}-\frac{R T}{2 F} \ln \frac{p H}{\left[10^{-7}\right]^{2}}\right)-\left(E_{a n}^{0}-\frac{R T}{8 F} \ln \frac{\left[\mathrm{CH}_{3} \mathrm{COO}^{-}\right]}{\left[\mathrm{HCO}_{3}^{-}\right]^{2}\left[10^{-7}\right]^{9}}\right)$

where $E_{c a}$ and $E_{a n}$ represent the theoretical cathode and anode potential from the Nernst equation.

We calculated concentration overpotential related to a high cathode $\mathrm{pH}\left(\eta_{p H}\right)$ by measuring the observed $\mathrm{pH}$ difference between bulk liquid in the anode and cathode, and using the relationship of $60.1 \mathrm{mV}$ of overpotential per one unit that the cathode $\mathrm{pH}$ is higher than the anode $\mathrm{pH}$ at $30^{\circ} \mathrm{C}$. We determined Ohmic overpotential from the Ohmic resistance $\left(R_{\text {Ohmic }} ;\right.$ Ohm $\left.\mathrm{cm}^{2}\right)$ measured using EIS.

$\eta_{\text {Ohmic }}=j \cdot R_{\text {Ohmic }}$

We calculated the anode overpotential from the following equation,

$\eta_{a n}=E_{a n, o b s e r v e d}-E_{a n}$

We assumed that the remainder of the applied voltage is due to the cathode overpotential.

For the $j-V$ curve shown in Figure $1 \mathrm{a}$, we used $100 \mathrm{mM} \mathrm{NaOH}$ as the catholyte. This in itself creates the concentration overpotential due to a high cathode $\mathrm{pH}$. However, this was out of convenience for the experimental protocol. Even for MECs that are operated with $\mathrm{NaCl}$ electrolyte or buffers, the increase in cathode $\mathrm{pH}$ is a widely observed phenomenon [39-41]. We show in Figure S4 how the cathode $\mathrm{pH}$ increases over time up to almost 13 if we use a $100 \mathrm{mM} \mathrm{NaCl}$ solution at the cathode.

As shown in Figure 1a, at a high current density $\left(\sim 10 \mathrm{~A} \mathrm{~m}^{-2}\right)$ where the total applied potential was $1.092 \pm 0.017 \mathrm{~V}$, the cathode has the largest fraction of the overpotential $(0.429 \pm 0.040 \mathrm{~V})$, followed by the concentration overpotential due to a high cathode $\mathrm{pH}(0.344 \pm 0.019 \mathrm{~V})$, the anode overpotential $(0.153 \pm 0.012 \mathrm{~V})$, and the Ohmic overpotential $(0.085 \pm 0.002 \mathrm{~V})$. Energy losses associated with the anode are usually not avoidable because they relate to the concentration gradients of reactants and 
products in the anode biofilm (substrate and proton), intracellular potential losses (ARB metabolism), and the extracellular potential losses (EET to anode) [42-43]. The anode overpotential is typically $0.1-0.3 \mathrm{~V}$ depending on the current density [43-44]. This is reflected in the Nernst-Monod equation used for modeling ARB, in which the mid-point potential, which results in half the maximum current density production, is only $\sim 0.1$ to $0.15 \mathrm{~V}$ more positive of the theoretical anode potential for many pure and mixed cultures $[13,33,45]$. In this case, the anode overpotential $(0.153 \pm 0.012 \mathrm{~V})$ is within range of what is known for ARB with an efficient metabolism and EET mechanism. Therefore, we should focus on the energy losses from concentration overpotential due to a high cathode $\mathrm{pH}$ and cathode overpotential to improve the voltage efficiency.

\subsection{Effect of $\mathrm{CO}_{2}$ addition to the cathode}

The $\mathrm{pH}$ imbalance between the anode and the cathode in MXCs always results in a higher $\mathrm{pH}$ at the cathode [2,34]. Since an increase in one $\mathrm{pH}$ unit decreases the redox potential for the hydrogen evolution reaction by $60.1 \mathrm{mV}$ (at $30^{\circ} \mathrm{C}$ ), this results in a large concentration overpotential. In the case shown in Figure 1a, the $\mathrm{pH}$ difference between the two chambers was 6.0 units, and so the concentration overpotential was $0.361 \mathrm{~V}$. We have previously tested a strategy whereby adding $\mathrm{CO}_{2}$ to the cathode can reduce the $\mathrm{pH}$, and thus reduce the concentration overpotential in air-cathode MFCs which include the oxygen reduction reaction $[34,36]$. We tested this strategy for our flatplate MEC design. In MECs with a liquid catholyte, hydroxide ion $\left(\mathrm{OH}^{-}\right)$can be combined with the added $\mathrm{CO}_{2}$ to form bicarbonate $\left(\mathrm{HCO}_{3}{ }^{-}\right)$and/or carbonate $\left(\mathrm{CO}_{3}{ }^{-}\right)$ anions (Figure S5). These anions dissolved in catholyte will buffer the $\mathrm{pH}$ close to their $\mathrm{p} K_{a}$ values of 10.3 and 6.3 for the $\mathrm{HCO}_{3}{ }^{-} / \mathrm{CO}_{3}{ }^{-}$and $\mathrm{CO}_{2} / \mathrm{HCO}_{3}{ }^{-}$couples, respectively. This is advantageous in decreasing the $\mathrm{pH}$-related concentration overpotential. A previous study shows that the pHs of catholytes were $\sim 5.9$ and $\sim 6.5$ of non-buffer and buffer solution with $\mathrm{CO}_{2}$ addition to cathode in MFC [38]. 
We show in Figure 2 the effect of adding $\mathrm{CO}_{2}$ to the cathode on the applied voltage and the cathode $\mathrm{pH}$ at a high current density $\left(\sim 18.5 \mathrm{~A} \mathrm{~m}^{-2}\right)$. As soon as we introduced $\mathrm{CO}_{2}$ into the cathode chambers of the MEC, the applied voltage decreased from 1.285 to $1.083 \mathrm{~V}$. This represents a decrease in the overpotential of $0.202 \mathrm{~V}$. The cathode $\mathrm{pH}$ decreased by roughly 5 units. This should result in a decrease in the applied voltage of $\sim 0.301 \mathrm{~V}$. While the change we observe is smaller than this, it could be due to a higher local cathode $\mathrm{pH}$ than that measured in the bulk solution of the cathode chambers. This overpotential could then thus be included in the cathode overpotential for which we do not distinguish between the activation losses and the concentration overpotential due to higher surface $\mathrm{pH}$ than bulk solution. We have observed such phenomenon in MFC cathodes before [34]. Nonetheless, we confirmed that adding $\mathrm{CO}_{2}$ to the cathode represents a great opportunity to reduce significantly the applied voltage in MECs. This improvement is greater than the previous report in aircathode MFCs [37], which shows the improvement of the operational voltage of the MFC by 0.08 and $0.12 \mathrm{~V}$ with 5 and $10 \%$ of $\mathrm{CO}_{2}$ addition to the MFC cathode, respectively. The larger improvement we observed could be due to higher concentration of $\mathrm{CO}_{2}$ (100\%) added to the cathode in our study.

To further confirm that the benefit of $\mathrm{CO}_{2}$ is primarily on the $\mathrm{pH}$, and not necessarily on the cathode activation overpotential, we performed EIS measurements on the cathode, at various cathode potentials. Through these measurements, we determined the overall cathode resistance at each potential. The results from these measurements are shown in Figure 3. In Figure 3a, we show the cathode potential vs. the cathode area-specific resistance, from which it is apparent that the main impact of $\mathrm{CO}_{2}$ is on changing the cathode potential at which a given current density is obtained. However, the overall shape of the curve remains similar, suggesting that the catalyst properties have not changed. This is further exemplified in Figure $3 \mathrm{~b}$, where the current 
density vs. the cathode area-specific resistance relationship stays the same irrespective of adding $\mathrm{CO}_{2}$. These results indicate that $\mathrm{CO}_{2}$ only affects the performance by decreasing the $\mathrm{pH}$ in the cathode chamber without resulting in any cathode catalytic changes.

Next we characterized the flat-plate MEC the same way as in Figure 1a, but this time while continuously adding $\mathrm{CO}_{2}$ to the cathode chambers (Experiment 2). A comparison of the complete characterization with (Figure $1 \mathrm{~b}$ ) and without $\mathrm{CO}_{2}$ is shown in Figure 1. Adding $\mathrm{CO}_{2}$ to the cathode chamber almost completely eliminated $\mathrm{pH}$ related concentration overpotential (only $0.027 \pm 0.013 \mathrm{~V}$ ). At a current density of $10 \mathrm{~A}$ $\mathrm{m}^{-2}$, we reduced the total applied voltage from 1.092 to $0.859 \mathrm{~V}$, which is amongst the best reported performances for MECs in literature [23-26]. There are few studies having exceptional high current densities $\left(>16 \mathrm{~A} \mathrm{~m}^{-2}\right.$ ) with $1 \mathrm{~V}$ of applied voltage $[44,46]$. The high performance might result from a good reactor design with a high rate of flow through recirculation of anolyte and catholyte (hydraulic retention times [HRTs] $\approx 1 \sim 2$ minutes). The recirculation helps mass transport of reactants and products to and from anode and cathode; this might be one of the reasons for their high performance. The energy usage for high rate of recirculation with pump was not evaluated.

Even though the overall overpotential was reduced with addition of $\mathrm{CO}_{2}$ to the cathode chamber, the Ohmic overpotential increased, and this is likely due to a shift in the predominant species being transported through the $\mathrm{AEM}$ from $\mathrm{OH}^{-}$to carbonate or bicarbonate. We next focused on decreasing this Ohmic overpotential to ensure the maximum benefit of adding $\mathrm{CO}_{2}$ for $\mathrm{pH}$ control. In addition, this leaves cathode overpotential as the major overpotential in the system $(0.457 \pm 0.023 \mathrm{~V})$, and thus we focused also on testing other cathode catalysts with the aim of reducing the overall applied voltage.

\subsection{Material selection for reducing the Ohmic and cathode overpotentials}




\subsubsection{Membranes}

We show in Figure 4 the area specific resistance to ion transport for five different AEMs in $100 \mathrm{mM}$ bicarbonate solution. While AMI-7001 is a standard AEM that have been used in various laboratory MXC studies [14, 38, 47], it had the largest resistances to transport of bicarbonate of all the membranes we tested. The FAA, FAB, and A201 membranes provided significantly less resistance to bicarbonate transport compared to the AMI-7001 and I-200 membranes. The result is consistent with the type of membrane, i.e. "homogeneous" or "heterogeneous." Heterogeneous membranes (AMI7001 and I-200) have a backing material, providing greater mechanical strength but an increase in thickness and thus higher ion transport resistance. On the other hand, homogeneous membranes (FAA, FAB, and A201) are the opposite since they are made from finer resin particles, thus resulting in thinner and flexible membranes with lower resistance [48-49] (see Table 1 for thicknesses for each membrane). Since FAA has also better stability at higher $\mathrm{pH}$ compared to AMI-7001 (Table 1), we selected FAA as the membrane to replace AMI-7001 in the next phase of our MEC testing.

\subsubsection{Cathodes}

Even though $\mathrm{CO}_{2}$ has a benefit in decreasing the concentration overpotential, the cathode overpotential also represents one of the major overpotentials. A Pt-based cathode can decrease the cathodic activation losses most effectively, but Pt is expensive. Thus, there have been many studies to develop efficient catalysts for reducing cathodic activation overpotential with non-noble metals [44, 50-52]. Many reports show that nickel or Ni-based cathodes are effective in decreasing the hydrogen evolution reaction overpotential $[44,53-54]$. Therefore, to decrease the cathode overpotential by selecting a good low-cost catalyst, we chose a commercially available Ni mesh, and tested its performance against the SS mesh as a comparison (Figure 5). The nickel mesh (Ni 200) had less overpotential compared to the SS mesh especially at 
high current density. At $10 \mathrm{~A} \mathrm{~m}^{-2}$, cathode potential is higher by $0.12( \pm 0.002) \mathrm{V}$ with $\mathrm{Ni}$ 200 mesh indicating a lower activation barrier to produce $\mathrm{H}_{2}$. This could be because of higher catalytic activity of pure nickel vs. in an alloy, such as in stainless steel, or related to the specific configuration we used for the meshes (for e.g. open area, mesh size etc. - see Table S1 in Supporting Information).

\subsection{Characterization of overpotentials in MEC with improved materials}

With the Ni mesh cathode and FAA membrane, we performed the same characterization experiments for the MEC as we did with the MEC with SS mesh cathode and AMI-7001 membrane, both without and with adding $\mathrm{CO}_{2}$ to the cathode chambers (Experiment 3 and 4, respectively). Figure 6 shows the $j-V$ curve with the applied voltage separated into the various overpotentials. We also summarize each individual overpotential at $10 \mathrm{~A} \mathrm{~m}^{-2}$ in Table 3.

At $10 \mathrm{~A} \mathrm{~m}^{-2}$, the total overpotential without adding $\mathrm{CO}_{2}$ to the cathode was 0.989 $\pm 0.017 \mathrm{~V}$, a significant decrease over the values obtained before the materials improvement $(1.092 \pm 0.017 \mathrm{~V})$. The FAA membrane decreased the Ohmic overpotential by $\sim 52 \mathrm{mV}$ from $0.085 \pm 0.002 \mathrm{~V}$ with $\mathrm{AMI}-7001$ to $0.033 \pm 0.004 \mathrm{~V}$ at $10 \mathrm{~A}$ $\mathrm{m}^{-2}$. The cathode overpotential decreased from $0.429 \pm 0.040 \mathrm{~V}$ to $0.405 \pm 0.036 \mathrm{~V}$. The FAA membrane allowed for a slightly lower $\mathrm{pH}$ in the cathode chamber, which also resulted in a decrease in the concentration overpotential due to a higher cathode $\mathrm{pH}$ $(0.279 \pm 0.011 \mathrm{~V}$ overpotential with FAA vs. $0.344 \pm 0.019 \mathrm{~V}$ overpotential with AMI7001). The overall reduction in the applied voltage however was smaller than the improvements in these overpotentials, because the anode overpotential was slightly higher at $0.199 \pm 0.013 \mathrm{~V}$ vs. $0.153 \pm 0.012 \mathrm{~V}$

When adding $\mathrm{CO}_{2}$ to the cathode chambers, the applied voltage at $10 \mathrm{~A} \mathrm{~m}^{-2}$ was $0.888 \pm 0.022 \mathrm{~V}$, which does not represent an improvement over the previous MEC before including new materials $(0.859 \pm 0.001 \mathrm{~V})$. This was despite improvement in the 
Ohmic overpotential, which decreased from $0.125 \mathrm{~V} \pm 0.007$ to $0.035 \pm 0.003 \mathrm{~V}$ with the FAA membrane. The largest part of the overpotential $(0.513 \pm 0.021 \mathrm{~V})$ in this case was from the cathode overpotential. There are several possible reasons for this. It is possible that there was a local high $\mathrm{pH}$ on the cathode surface, despite a lower bulk $\mathrm{pH}$ with adding $\mathrm{CO}_{2}$, which could result in a higher cathode overpotential, which includes any losses due to local concentration gradients.

In addition, the characterization with $\mathrm{CO}_{2}$ added to the cathode was done after several days of operation of the MEC, which could have resulted in inhibition of the nickel catalyst. It has previously been reported that with long-term operation (> 1 month) with a Ni foam cathode, the overpotential increased, but the exact mechanisms of this change in performance are not known [44]. One possible mechanism is the formation of nickel hydride, which has been shown to diminish the catalytic properties of $\mathrm{Ni}$ [51]. In addition, another possible cause could be the decrease of active surface area due to either the $\mathrm{H}_{2}$ or $\mathrm{CO}_{2}$ bubbles trapped in the mesh (Figure S7), which were evident while operating the cathode in this fashion. This would result not only in higher activation losses due to reduced surface area, but also possibly concentration overpotential due to accumulation of $\mathrm{H}_{2}$ on the reaction surface.

\subsection{Implications}

We characterized the applied voltage in flat-plate MECs as individual overpotentials from different phenomena. This is of great theoretical and practical importance in order to optimize design and increase voltage efficiency. In our flat-plate MECs, low overpotentials at high current densities were observed with (i) high-surface area anode, (ii) commercially available cathodes and membranes, and (iii) $\mathrm{CO}_{2}$ addition to the cathode.

Overpotentials arising from each different phenomenon in MECs would vary based on the materials (e.g. membrane, microbial and inorganic catalysts, and solution 
properties and concentrations) and reactor designs. Different researchers use their own materials and design preferences for achieving their performance goals. However, the type of characterization we present here can serve as a first step to compare the voltage efficiency among various studies.

$\mathrm{CO}_{2}(100 \%)$ addition to the cathode eliminated concentration overpotential due to a high cathode $\mathrm{pH}$, just like in air-cathode MFCs as shown earlier [34, 37]. We want to note here that while we used a two-chambered MEC where $\mathrm{pH}$ difference between the anode and cathode is directly apparent due to the use of a membrane, we have shown that local gradients could also cause a Nernstian concentration overpotential at the cathode in single-chambered systems, which can be decreased or eliminated using $\mathrm{CO}_{2}$ [34]. Recycle of the $\mathrm{CO}_{2}$ produced in the anode from oxidation of organics would be the ideal scenario. In the present study, we use the optimum system using pure $\mathrm{CO}_{2}$ and fast recirculation with pump. However, how $\mathrm{CO}_{2}$ is returned from the anode to the cathode needs to be optimized further, especially when dealing with real wastes at the anode.

Homogeneous membrane (FAA) could decrease the Ohmic overpotential with better ionic transport. Especially, the lower membrane resistance was beneficial to allow the membrane to facilitate anions transport $\left(\mathrm{OH}^{-}, \mathrm{HCO}_{3}{ }^{-}, \mathrm{CO}_{3}{ }^{2-}\right)$ with $\mathrm{CO}_{2}$ addition. However, among the overpotentials we categorized, Ohmic overpotential was the smallest, especially at lower current density $\left(<5 \mathrm{~A} \mathrm{~m}^{-2}\right)$. Since current densities when fed with real wastewater could be relatively smaller compared to synthetic medium, we may employ heterogeneous membranes or separators due to the small Ohmic overpotential, as they are mechanically stronger for real wastewater, and economically feasible. We estimate that in any case it should not be difficult to minimize the Ohmic overpotential to $<0.1 \mathrm{~V}$. 
The cathode overpotential is still a major problem in our reactor design when we used the commercially available mesh-type cathodes without using any precious metal, as well as widely recognized by many studies [2, 34, 55-56]. Even though we reduced the concentration overpotential due to a high cathode $\mathrm{pH}$ through addition of $\mathrm{CO}_{2}$, local concentration gradients could still cause a Nernstian concentration overpotential. Overcoming this would require optimizing mass transport between the anode and the cathode further, possibly through using novel designs and/or improved hydrodynamics at the local surfaces. In traditional electrolysis cells, cathode overpotential, although being the highest of all overpotentials, is significantly less than in MECs. We estimate that the cathode overpotential in MECs through further optimization could possibly be reduced to $\sim 0.2 \mathrm{~V}$

Considering all the improvements that can be made, as well as the $0.1-0.3 \mathrm{~V}$ of overpotential needed at the anode, we estimate that the total applied voltage in MECs at high current densities (e.g. $>10 \mathrm{~A} \mathrm{~m}^{-2}$ ) could be reduced to $\sim 0.7 \mathrm{~V}$. This should thus be the goal of all future optimization studies that hope to address the scalability of MECs.

\section{Acknowledgement}

We acknowledge the Office of Naval Research (grant \# N00014121034) and the Department of Defense's SERDP program (project \# ER-2239) for providing the funding for this study.

\section{References}

[1] B.E. Logan, B. Hamelers, R. Rozendal, U. Schröder, J. Keller, S. Freguia, P. Aelterman, W. Verstraete, K. Rabaey, Microbial Fuel Cells: Methodology and Technology, Environ. Sci. Technol. 40 (2006) 5181-5192. 
[2] R. Rozendal, H.V.M. Hamelers, G.J.W. Euverink, S.J. Metz, C.J.N. Buisman, Principle and perspectives of hydrogen production through biocatalyzed electrolysis, Int. J. Hydrogen Energ. 31 (2006) 1632-1640.

[3] K. Rabaey, R. Rozendal, Microbial electrosynthesis - revisiting the electrical route for microbial production, Nat. Rev. Microbiol. 8 (2010) 706-716.

[4] R. Rozendal, E. Leone, J. Keller, K. Rabaey, Efficient hydrogen peroxide generation from organic matter in a bioelectrochemical system, Electrochem. Commun. 11 (2009) 1752-1755.

[5] K.P. Nevin, S.A. Hensley, A.E. Franks, Z.M. Summers, J.H. Ou, T.L. Woodard, O.L. Snoeyenbos-West, D.R. Lovley, Electrosynthesis of organic compounds from carbon dioxide catalyzed by a diversity of acetogenic microorganisms, Appl. Environ. Microbiol. 77 (2011) 2882-2886.

[6] C.I. Torres, A.K. Marcus, B.E. Rittmann, Kinetics of consumption of fermentation products by anode-respiring bacteria, Appl. Microbiol. Biotechnol. 77 (2007) 689697.

[7] V. Vologni, R. Kakarla, I. Angelidaki, B. Min, Increased power generation from primary sludge by a submersible microbial fuel cell and optimum operational conditions, Bioprocess Biosyst. Eng. 36 (2013) 635-642.

[8] H.-S. Lee, P. Parameswaran, A.K. Marcus, C.I. Torres, B.E. Rittmann, Evaluation of energy-conversion efficiencies in microbial fuel cells (MFCs) utilizing fermentable and non-fermentable substrates, Water Res. 42 (2008) 1501-1510.

[9] H.-S. Lee, W.F.J. Vermass, B.E. Rittmann, Biological hydrogen production: prospects and challenges, Trends Biotechnol. 28 (2010) 262-271.

[10] N.S. Malvankar, M. Vargas, K.P. Nevin, A.E. Franks, C. Leang, B.C. Kim, K. Inoue, T. Mester, S.F. Covalla, J.P. Johnson, V.M. Rotello, M.T. Tuominen, D.R. Lovley, 
Tunable metallic-like conductivity in microbial nanowire networks, Nat. Nanotechnol. 6 (2011) 573-579.

[11] D.R. Bond, S.M. Strycharz-Glaven, L.M. Tender, C.I. Torres, On electron transport through geobacter biofilms, ChemSusChem 5 (2012) 1-8.

[12] S. Pirbadian, M.Y. El-Naggar, Multistep hopping and extracellular charge transfer in microbial redox chains, Phys. Chem. Ch. Ph. 14 (2012) 13802-13808.

[13] R.A. Yoho, S.C. Popat, C.I. Torres, Dynamic Potential-Dependent Electron Transport Pathway Shifts in Anode Biofilms of Geobacter sulfurreducens, ChemSusChem 7 (2014) 3413-3419.

[14] P. Parameswaran, C.I. Torres, H.-S. Lee, R. Krajmalnik-Brown, B.E. Rittmann, Syntrophic Interactions Among Anode Respiring Bacteria (ARB) and Non-ARB in a Biofilm Anode: Electron Balances, Biotechnol. Bioeng. 103 (2009) 513-523.

[15] P.D. Kiely, G. Rader, J.M. Regan, B.E. Logan, Long-term cathode performance and the microbial communities that develop in microbial fuel cells fed different fermentation endproducts, Bioresource Technol. 102 (2011) 361-366.

[16] T.H. Pham, N. Boon, P. Aelterman, P. Clauwaert, L.D. Schamphelaire, L. Vanhaecke, K.D. Maeyer, M. Höfte, W. Verstraete, K. Rabaey, Metabolites produced by Pseudomonas sp. enable a Grampositive bacterium to achieve extracellular electron transfer, Appl. Microbiol. Biotechnol. 77 (2008) 1119-1129.

[17] D. Sun, D.F. Call, P.D. Kiely, A. Wang, B.E. Logan, Syntrophic interactions improve power production in formic acid fed MFCs operated with set anode potentials or fixed resistances, Biotechnol. Bioeng. 109 (2012) 405-414.

[18] J. Liu, F. Zhang, W. He, W. Yang, Y. Feng, B.E. Logan, A microbial fluidized electrode electrolysis cell (MFEEC) for enhanced hydrogen production, J. Power Sources 271 (2014) 530-533. 
[19] D.L. Hoskins, X. Zhang, M.A. Hickner, B.E. Logan, Spray-on polyvinyl alcohol separators and impact on power production in air-cathode microbial fuel cells with different solution conductivities, Bioresource Technol. 172 (2014) 156-161.

[20] F. Zhang, T. Saito, S. Cheng, M.A. Hickner, B.E. Logan, Microbial fuel cells cathodes constructed from stainless steel mesh that use poly(dimethylsiloxane) diffusion layers. Environ. Sci. Technol. 44 (2010) 1490-1495.

[21] F. Harnisch, U. Schröder, From MFC to MXC: chemical and biological cathodes and their potential for microbial bioelectrochemical systems, Chem. Soc. Rev. 39 (2010) 4433-4438.

[22] C.I. Torres, On the importance of identifying, characterizing, and predicting fundamental phenomena towards microbial electrochemistry applications, Curr. Opin. Biotech. 27 (2014) 107-114.

[23] J. An, H.-S. Lee, Implication of endogenous decay current and quantification of soluble microbial products (SMP) in microbial electrolysis cells, RSC Adv. 3 (2013) $14021-14028$.

[24] B. Tartakovsky, P. Mehta, G. Santoyo, S.R. Guiot, Maximizing hydrogen production in a microbial electrolysis cell by real-time optimization of applied voltage, Int. J. Hydrogen Energ. 36 (2011) 10557-10564.

[25] T.H.J.A. Sleutels, A.T. Heijne, C.J.N. Buisman, H.V.M. Hamelers, Steady-state performance and chemical efficiency of Microbial Electrolysis Cells, Int. J. Hydrogen Energ. 38 (2013) 7201-7208.

[26] Y. Zhang, M.D. Merrill, B.E. Logan, The use and optimization of stainless steel mesh cathodes in microbial electrolysis cells, Int. J. Hydrogen Energ. 35 (2010) 12020-12028. 
[27] Y. Wang, K.S. Chen, J. Mishler, S.C. Cho, X.C. Adroher, A review of polymer electrolyte membrane fuel cells: Technology, applications, and needs on fundamental research, Appl. Energ. 88 (2011) 981-1007.

[28] A. Ursúa, L.M. Gandía, P. Sanchis, Hydrogen production from water electrolysis: current status and future trends, PIEEE. 100 (2012) 410-426.

[29] R. O'Hayre, S.W. Cha, W. Colella, F.B. Prinz, Fuel Cell Fundamentals, Wiley, New York, 2006.

[30] T.H. Pham, K. Rabaey, P. Aelterman, P. Clauwaert, L.D. Schamphelaire, N. Boon, W. Verstraete, Pham, T. H., K. Rabaey, P. Aelterman, P. Clauwaert, L. De Schamphelaire, N. Boon, and W. Verstraete. Microbial fuel cells in relation to conventional anaerobic digestion technology, Eng. Life Sci. 6 (2006) 285-292.

[31] H. Liu, B.E. Logan, Electricity generation using an air-cathode single chamber microbial fuel cell in the presence and absence of a proton exchange membrane, Environ. Sci. Technol. 38 (2004) 38, 4040-4046.

[32] H. Liu, H. Hu, J. Chignell, Y. Fan, Microbial electrolysis: novel technology for hydrogen production from biomass, Biofuels 1 (2010), 129-142.

[33] C.I. Torres, A.K. Marcus, B.E. Rittmann, Proton transport inside the biofilm limits electrical current generation by anode-respiring bacteria, Biotechnol. Bioeng. 100 (2008) 872-881.

[34] S.C. Popat, D. Ki, B.E. Rittmann, C.I. Torres, Importance of $\mathrm{OH}^{-}$transport from cathodes in microbial fuel cells, ChemSusChem 5 (2012) 1071-1079.

[35] D. Ki, P. Parameswaran, S.C. Popat, B.E. Rittmann, C.I. Torres, Effects of prefermentation and pulsed-electric-field treatment of primary sludge in microbial electrochemical cells, Bioresource Technol. (2015), in print.

[36] C.I. Torres, R. Krajmalnik-Brown, P. Parameswaran, A.K. Marcus, G. Wanger, Y.A. Gorby, B.E. Rittmann, Selecting anode-respiring bacteria based on anode 
potential: phylogenetic, electrochemical, and microscopic characterization, Environ. Sci. Technol. 43 (2009) 9519-9524.

[37] C.I. Torres, H.S. Lee, B.E. Rittmann, Carbonate species as $\mathrm{OH}^{-}$carriers for decreasing the ph gradient between cathode and anode in biological fuel cells, Environ. Sci. Technol. 42 (2008) 8773-8777.

[38] J.J. Fornero, M.Rosenbaum, M.A. Cotta, L.T. Angenent, Carbon Dioxide Addition to Microbial Fuel Cell Cathodes Maintains Sustainable Catholyte $\mathrm{pH}$ and Improves Anolyte pH , Alkalinity , and Conductivity, Environ. Sci. Technol. 44 (2010) 27282734.

[39] R.A. Rozendal, T.H.J.A. Sleutels, H.V.M. Hamelers, C.J.N. Buisman, Effect of the type of ion exchange membrane on performance, ion transport, and $\mathrm{pH}$ in biocatalyzed electrolysis of wastewater, Water Sci. Technol. 57 (2008) 1757-1762.

[40] T.H.J.A. Sleutels, H.V.M. Hamelers, R.A. Rozendal, C.J.N. Buisman, lon transport resistance in Microbial Electrolysis Cells with anion and cation exchange membranes, Int. J. Hydrogen Energ. 34 (2009) 3612-3620.

[41] J.-Y. Nam, B.E. Logan, Optimization of catholyte concentration and anolyte pHs in two chamber microbial electrolysis cells, Int. J. Hydrogen Energ. 37 (2012) 1862218628.

[42] C.I. Torres, A.K. Marcus, H.-S. Lee, P. Parameswaran, R. Krajmalnik-Brown, B.E. Rittmann, A kinetic perspective on extracellular electron transfer by anoderespiring bacteria, FEMS Microbiol. Rev. 34 (2010) 3-17.

[43] H.-S. Lee, B.E. Rittmann, Characterization of energy losses in an upflow singlechamber microbial electrolysis cell, Int. J. Hydrogen Energ. 35 (2010) 920-927.

[44] A.W. Jeremiasse, H.V.M Hamelers, M. Saakes, C.J.N. Buisman, Ni foam cathode enables high volumetric $\mathrm{H} 2$ production in a microbial electrolysis cell, Int. J. Hydrogen Energ. 35 (2010) 12716-12723. 
[45] C.I. Torres, A.K. Marcus, P. Parameswaran, B.E. Rittmann, Kinetic experiments for evaluating the Nernst-Monod model for anode-respiring bacteria (ARB) in a biofilm anode, Environ. Sci. Technol. 42 (2008) 6593-6507.

[46] T.H.J.A. Sleutels, R. Lodder, H.V.M. Hamelers, C.J.N. Buisman, Improved performance of porous bio-anodes in microbial electrolysis cells by enhancing mass and charge transport, Int. J. Hydrogen Energ. 34 (2009) 9655-9661.

[47] H. Liu, H. Hu, J. Chignell, Y. Fan, Microbial electrolysis: novel technology for hydrogen production from biomass, Biofuels 1 (2010), 129-142.

[48] P.V. Vyas, B.G. Shah, G.S. Trivedi, P. Ray, S.K. Adhikary, R. Rangarajan, Characterization of heterogeneous anion-exchange membrane, J. Membrane Sci. 187 (2001) 39-46.

[49] E. Güler, Anion exchange membrane design for reverse electrodialysis. PhD Dissertation, 2014.

[50] N.V. Krstajić, L. Gajić-Krstajić, U. Lačnjevac, B.M. Jović, S. Mora, V.D. Jović, Nonnoble metal composite cathodes for hydrogen evolution. Part I: The Ni-MoOx coatings electrodeposited from Watt's type bath containing $\mathrm{MoO}_{3}$ powder particles, Int. J. Hydrogen Energ. 36 (2011) 6441-6449.

[51] H. Hu, Y. Fan, H. Liu, Hydrogen production in single-chamber tubular microbial electrolysis cells using non-precious-metal catalysts, Int. J. Hydrogen Energ. 34 (2009) 8535-8542.

[52] A.M. Couper, D. Pletcher, F.C. Walsh, Electrode materials for electrosynthesis. Chem. Rev. 90 (1990) 837-865.

[53] P.A. Selembo, M.D. Merril, B.E. Logan, Hydrogen production with nickel powder cathode catalysts in microbial electrolysis cells, Int. J. Hydrogen Energ. 235 (2010) 428-437. 
[54] H. Hu, Y. Fan, H. Liu, Optimization of NiMo catalyst for hydrogen production in microbial electrolysis cells, Int. J. Hydrogen Energ. 35 (2010) 3227-3233.

[55] R.A. Rozendal, H.V.M. Hamelers, K. Rabaey, J. Keller, C.J.N. Busiman, Towards practical implementation of bioelectrochemical wastewater treatment, Trends Biotechnol. 26 (2008) 450-459.

[56] F. Zhao, F. Harnisch, U. Schröder, F. Scholz, P. Bogdanoff, I. Hermann, Challenges and constraints of using oxygen cathodes in microbial fuel cells, Environ. Sci. Technol. 40 (2006) 5193-5199. 


\section{Table Captions}

Table 1. List of membranes tested, including their supplier and physical properties.

Table 2. Operational conditions for flat-plate MEC.

Table 3. Individual overpotential characterized in flat-plate MEC at $10 \mathrm{~A} \mathrm{~m}^{-2}$ with and without $\mathrm{CO}_{2}$ addition to different cathodes ( $\mathrm{SS}$ and $\mathrm{Ni}$ ).

\section{Figure Captions}

Figure 1. Characterization of the applied voltage in the flat-plate MEC with AMI-70001 membrane and stainless steel mesh cathode (a) without and (b) with $\mathrm{CO}_{2}$ addition to cathode (Experiment 1 and 2, respectively). We performed chronoamperometry to plot $j$ $V$ curves after producing high current densities $\left(>15 \mathrm{~A} \mathrm{~m}^{-2}\right)$ in the MEC.

Figure 2. Decrease in applied voltage and cathode $\mathrm{pH}$ with $\mathrm{CO}_{2}$ addition to cathode. Current density was $18.5 \pm 0.3 \mathrm{~A} \mathrm{~m}^{-2}$.

Figure 3. Effect of $\mathrm{CO}_{2}$ on the cathode catalytic reaction: (a) cathode potential vs. the cathode area-specific resistance, (b) current density vs. the cathode area-specific resistance.

Figure 4. Resistances of various membranes tested in $100 \mathrm{mM} \mathrm{NaHCO}_{3}$.

Figure 5. Linear sweep voltammograms (LSVs) of stainless steel and nickel mesh cathodes at $\mathrm{pH} 13$.

Figure 6. Characterization of applied voltage in flat-plate MEC with FAA membrane and nickel mesh cathode (Experiment 3 [left] and Experiment 4[right]). All replicates followed the same trend and an additional representative set is shown in the Supporting Information (Figure S6). 


\section{Tables and Figures}

Table 1.

\begin{tabular}{ccccc} 
Type & Membrane & Supplier & Thickness & \\
& & & $(\mathrm{mm})$ & \\
\hline \multirow{2}{*}{ Heterogeneous } & AMl-7001 & Membranes International, USA & $0.50-0.51$ & $1-10$ \\
& Excellion I-200 & SnowPure, USA & $0.32-0.34$ & NR \\
\hline \multirow{2}{*}{ Homogenous } & Fumasep FAA & FuMa-Tech, Germany & $0.13-0.15$ & $6-13$ \\
& Fumasep FAB & FuMa-Tech, Germany & $0.10-0.13$ & $0-14$ \\
& A201 & Tokuyama, Japan & 0.028 & $0-14$
\end{tabular}

Table 2.

\begin{tabular}{cccc} 
& AEM & Cathode & $\mathrm{CO}_{2}$ addition to cathode \\
\hline Experiment 1 & AMI-7001 & Stainless Steel & No \\
Experiment 2 & AMI-7001 & Stainless Steel & Yes \\
Experiment 3 & Fumasep FAA & Nickel & No \\
Experiment 4 & Fumasep FAA & Nickel & Yes \\
\hline
\end{tabular}


Table 3.

\begin{tabular}{ccccc}
\hline Overpotential & $\mathrm{SS}$ without $\mathrm{CO}_{2}$ & $\mathrm{SS}$ with $\mathrm{CO}_{2}$ & $\mathrm{Ni}$ without $\mathrm{CO}_{2}$ & $\mathrm{Ni}$ with $\mathrm{CO}_{2}$ \\
\hline Anode & $0.153( \pm 0.012)$ & $0.168( \pm 0.016)$ & $0.199( \pm 0.013)$ & $0.210( \pm 0.014)$ \\
Cathode & $0.429( \pm 0.040)$ & $0.457( \pm 0.023)$ & $0.405( \pm 0.036)$ & $0.513( \pm 0.021)$ \\
Ohmic & $0.085( \pm 0.002)$ & $0.125( \pm 0.007)$ & $0.033( \pm 0.004)$ & $0.035( \pm 0.003)$ \\
$\mathrm{pH}$ & $0.344( \pm 0.019)$ & $0.027( \pm 0.013)$ & $0.279( \pm 0.011)$ & $0.032( \pm 0.002)$ \\
Theoretical & $0.081( \pm 0.000)$ & $0.081( \pm 0.000)$ & $0.091( \pm 0.001)$ & $0.098( \pm 0.001)$ \\
\hline Total & $1.092( \pm 0.017)$ & $0.859( \pm 0.001)$ & $0.989( \pm 0.017)$ & $0.888( \pm 0.022)$ \\
\hline
\end{tabular}


Figure 1
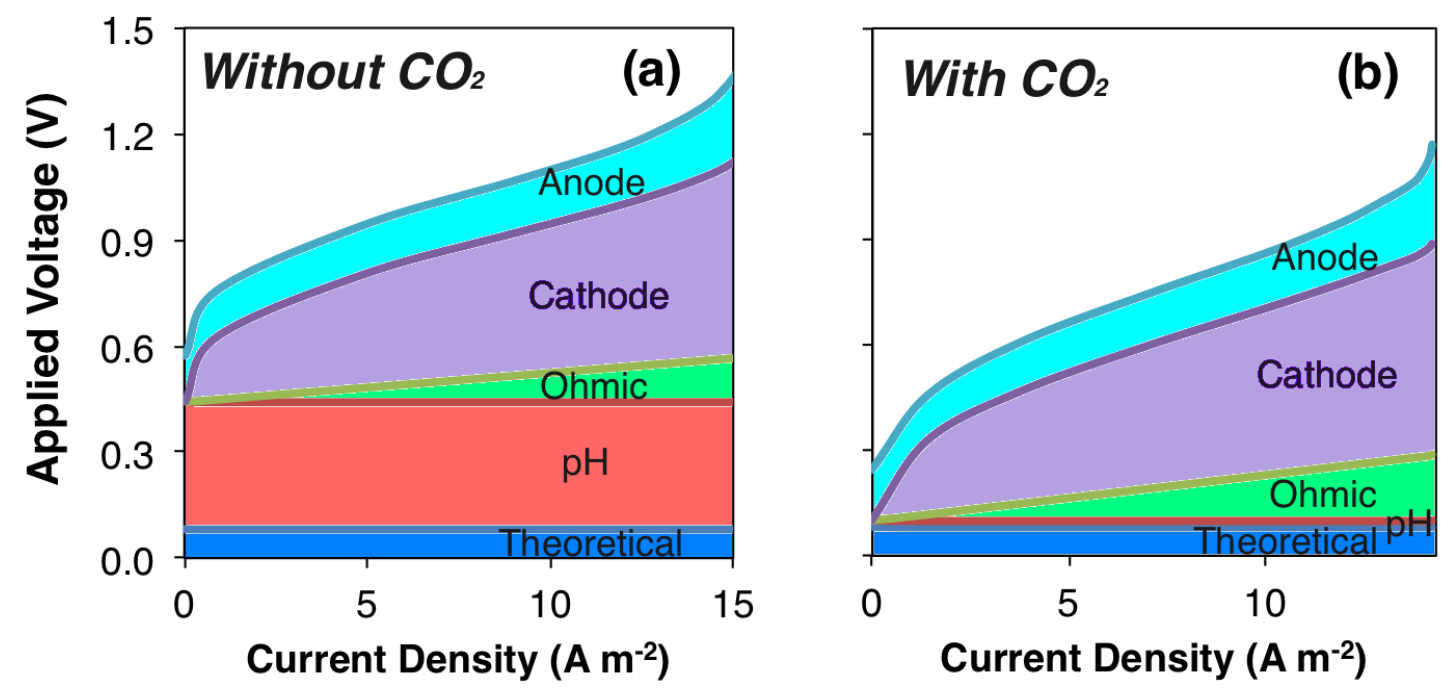

Figure 2

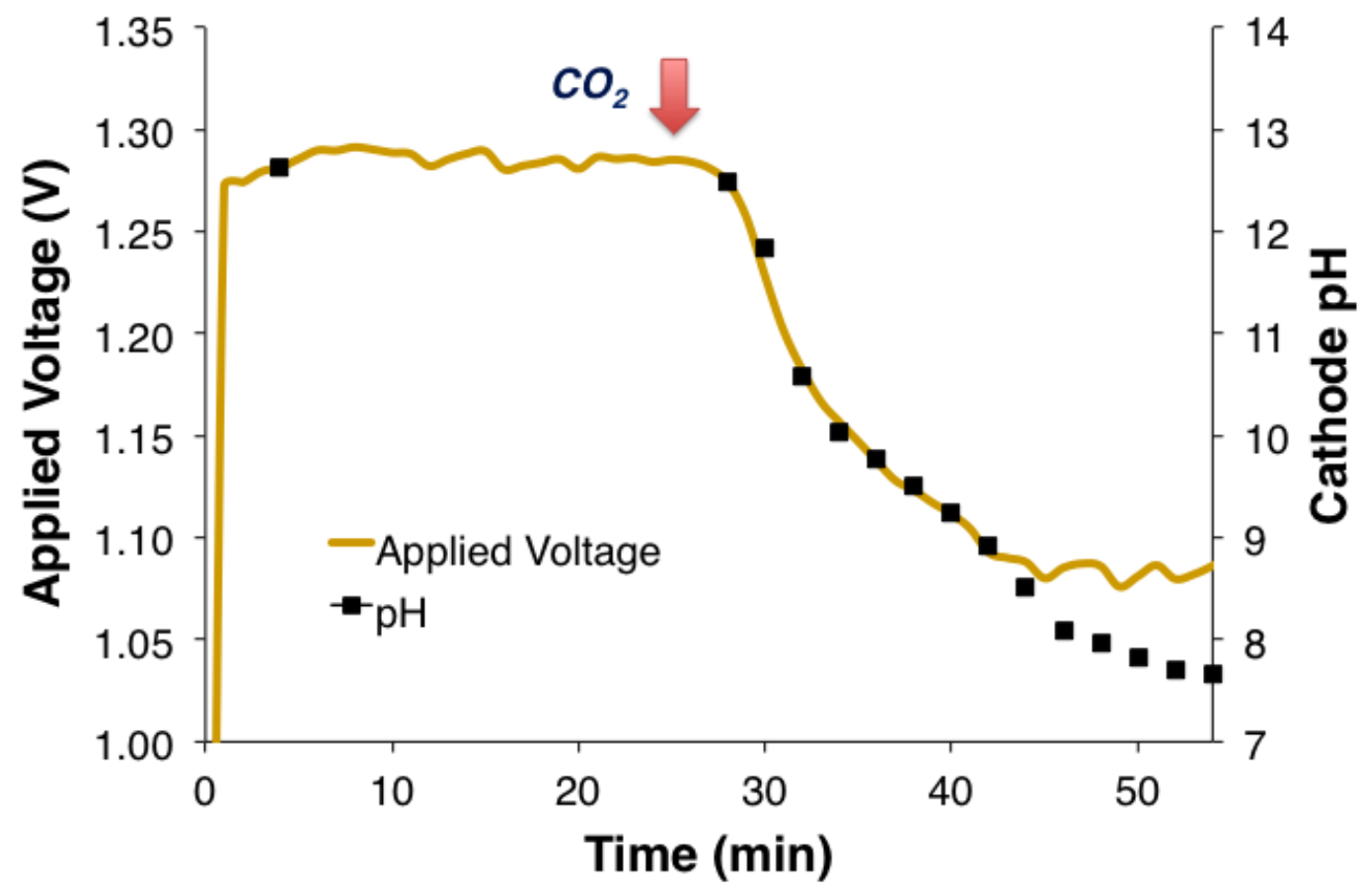


Figure 3
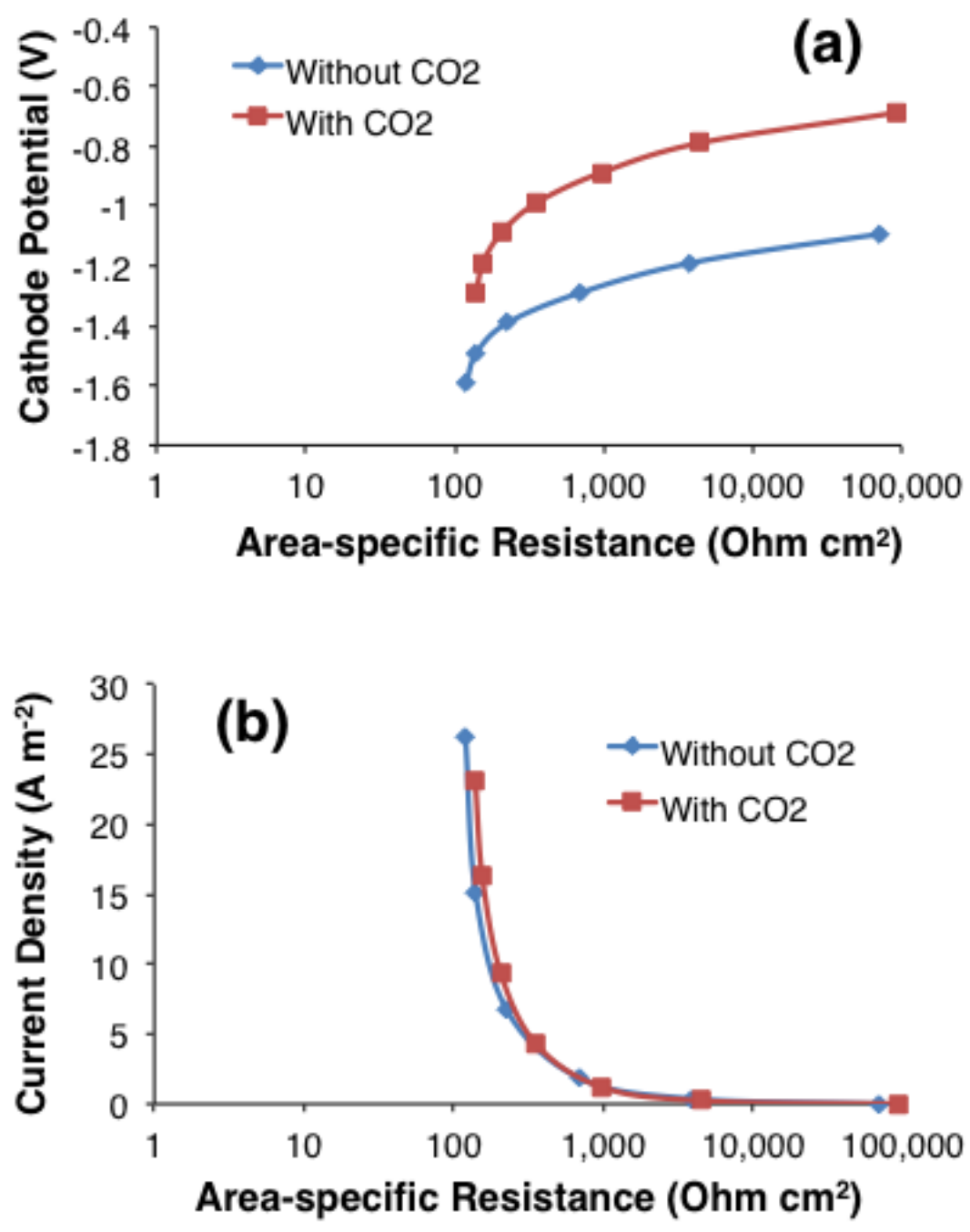
Figure 4

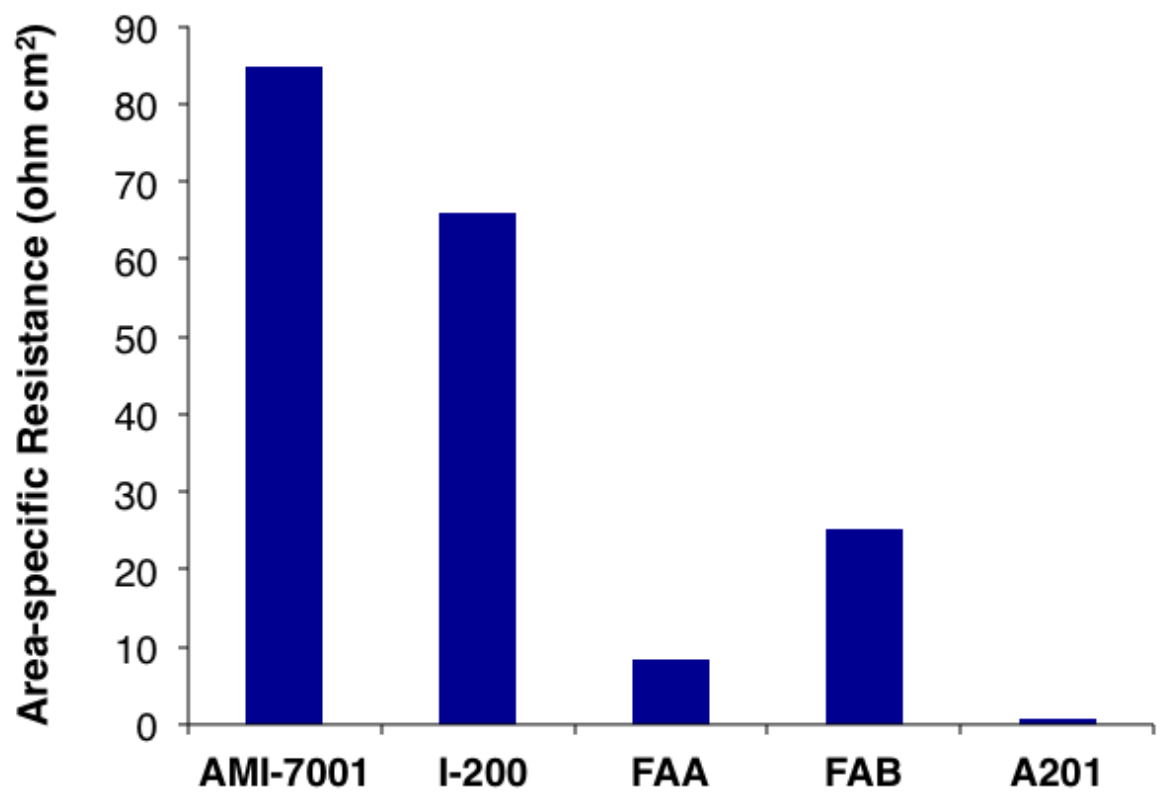

Figure 5

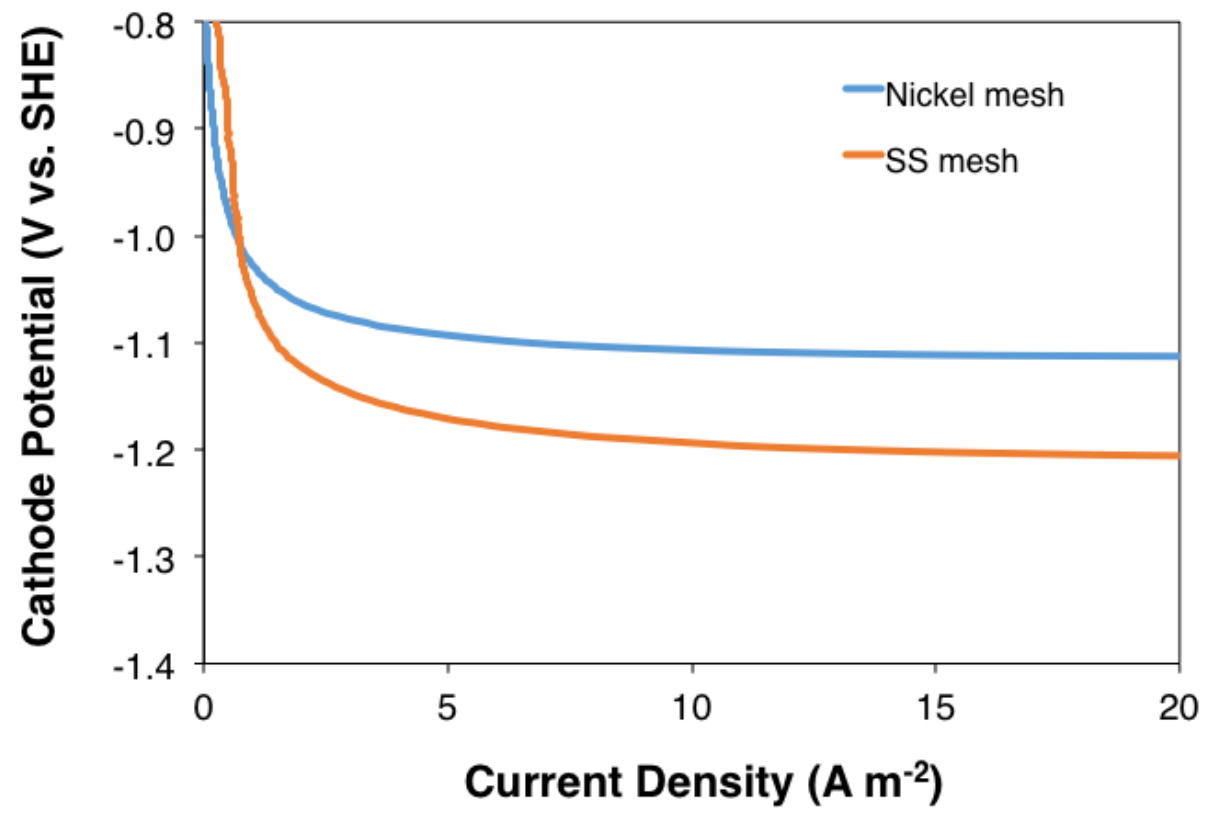


Figure 6
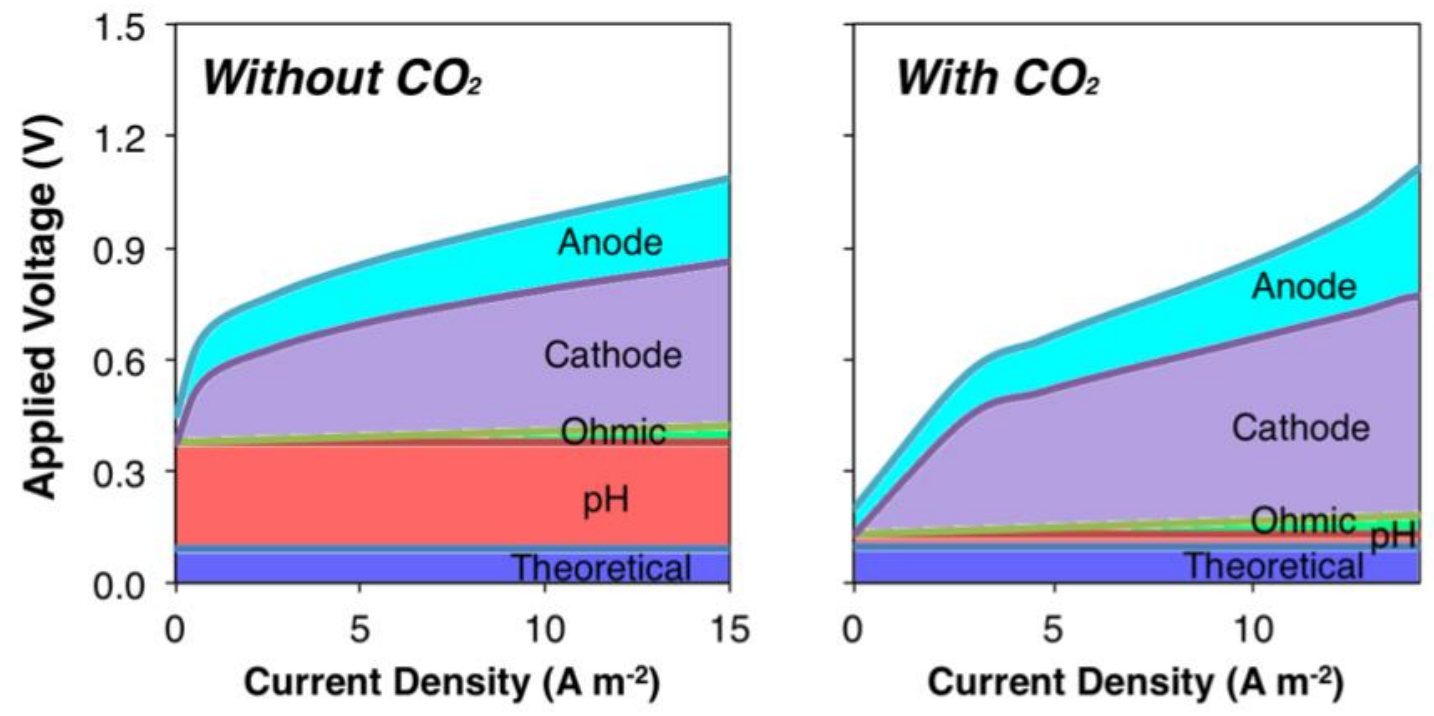